\title{
REFLECTIONS ON BURNOUT AND SELF-CARE MANAGEMENT IN SOCIAL WORK
}

\section{Rubeena Partab}

\section{INTRODUCTION}

Working with people with AIDS (PWAs) invariably requires that caregivers provide optimal care both to PWAs with serious illness and functional impairment, and to themselves.

Although this work is extremely rewarding, the enormity of the stress and strain it places on caregivers should not be under-estimated. While it is tacitly assumed that family and friends will provide care for the PWA, the caregiver is expected to possess an exceptional capacity for caring, despite the multifarious problems associated with this.

The enormity of the problem is exacerbated by escalating public healthcare costs and the human costs that are crippling care of PWAs.

\section{Statistical landscape of HIV/AIDS globally}

- 33.2 million people are infected with HIV.

- 25 million have died.

- In the US, out of a population of 300 million:

- 1.1 million people are infected with HIV, of whom $25 \%$ do not know their status;

- $49 \%$ of new HIV infections in men are among black people;

- $65 \%$ of new HIV infections in women are among black people;

- Black people make up 12\% of the US population (HIV-AIDS: 11 June 2008).

In South Africa the rate of infection is a bleak prospect for the many who are infected daily. The following statistics speak to the many realities that human service professionals are engaging with:

- In 2005 there were 590000 deaths recorded in South Africa;

- According to the Development Bank of Southern Africa, one in six South Africans is HIV positive;

- 7.6 million people are living with HIV;

- 900 people die from AIDS every day;

- Former Minister of Health, Manto Tshabalala-Msimang alluded in her Budget Speech in the National Assembly on 6 June 2008 to a 2007 survey, which indicated a decline of HIV prevalence of $1.2 \%$;

- The Department had distributed 309 million male and 3.6 million female condoms;

- More than $90 \%$ of public health facilities now provide voluntary counselling and testing;

- 450000 patients were on antiretroviral treatment (ARVs) at more than 310 accredited sites across the country;

- There had been 2505372 AIDS-related deaths in South Africa (Mail \& Guardian: 11 June 2008). 
Human service practitioners in particular are confronted daily with an increasing number of persons who are either affected or infected by this virus. This necessitates the training and education on HIV/AIDS, which comprise a substantial component of the student Social Work syllabi. At the University of KwaZulu-Natal entry-level students are exposed to a compulsory module on the disease and HIV/AIDS is a pervasive and integral component of the curriculum from the first to the fourth year. At level four a module is dedicated to issues surrounding the disease and its social and human impact. Students are acquainted with various aspects including: sexuality and safer sex counselling, HIV/AIDS testing, pre- and post-test counselling, legal and ethical issues, children and HIV/AIDS, gender, and AIDS and medicine.

Although the module effectively addresses pertinent and fundamental aspects of HIV/AIDS, students expressed the need to complement their acquired knowledge with interrogating problematic issues around this social disease. Furthermore, they believed that locating themselves within a self-evaluative exercise would facilitate and promote their understanding of the multidimensional intricacies of the disease and maximise service to their HIV/AIDSaffected clientele. The perceived utility and unexpressed objective also appeared to be harnessing their existing skills.

Working with HIV-positive people and PWAs left these students with a range of feelings and vacillating emotions. Some of the feelings identified included:

- hopelessness and helplessness;

- emotional overload and feelings of ambivalence;

- induced anxiety;

- burnout;

- fear of the disease;

- over-involvement and some degree of transference;

- difficulty of maintaining a positive attitude;

- awkwardness about transgender clients;

- acknowledging their limitations.

\section{Context}

Five female level-4 students who undertook their practice education at provincial hospitals, and ultimately worked extensively with PWAs, who constituted a sizeable portion of their caseload, approached the author, their group-work lecturer, about their concerns when working with PWAs. They requested assistance in comprehending the avalanche of their own feelings/emotions when interacting with HIV-positive clients.

The students reported that they felt inundated with residual feelings of hopelessness and helplessness, and were not able to identify how to appropriately ventilate, or to whom. They acknowledged that they were confronting reality and commented that HIV/AIDS became less academic. Some felt that they worked under tremendous pressure both at university and at the hospital and had to contend with the physiological effects of this stress, e.g. fatigue, headaches, etc., which ultimately impaired their functioning. There was consensus that, although they were conversant with the basic aetiology of the virus, they struggled with over-involvement and over-identification which impacted on their effective functioning and left them feeling depleted of energy to continue and engage positively with their clientele. Compassion fatigue and burnout become a constant reality. 
Gibson, Swartz and Sandenberg (2002) acknowledge the unmanageable feelings experienced by counsellors that could be debilitating to the therapeutic relationship between client and counsellor. Similarly Cunningham (2003) notes that caregivers are often stressed because they lack an understanding of HIV and the effects it has on the body and are not able to counteract these effects. Students said that although they were supervised on their cases weekly and attempted to share informally with each other, this did not adequately fulfil or address their individual needs. They also voiced their frustration at the lack of resources to address their concerns and offer coping strategies. Moreover, they identified the need to create a homeostatic balance between "caring and too much of caring", having realised that they often become overinvolved.

Miller (1999) agrees that developing appropriate expectations of what can be achieved is exceptionally important in coping. Studies in South Africa - including Armstrong, Bariyre, Finnegan, Nsubuga, Ottenweller, Sozi and Towell (2000), Ferreira, Ferreira and Gjourup (2000), Mazodze, Richards and Pennymon (2004), Lehmann and Zulu (2005) and Smit (2005) - have found that caregivers who are unable to establish emotional distance when working with people with HIV/AIDS will suffer from occupational stress and burnout.

Cunningham (2003) notes that many of the support systems available deal broadly with caregiving in general and are not specifically related to individuals who are caring for PWAs. She notes that much is borrowed from organisations dealing with Alzheimer's patients. These generalisations may lack specific applicability to HIV and may be inappropriate for the following reasons: difference in age amongst the two groups - PWAs are generally younger; medical information about HIV/AIDS is constantly changing compared to that for Alzheimer's, which makes it difficult for the caregiver to remain informed about the latest medical data; the stigma attached to HIV/AIDS is greater than that of most other diseases.

Cunningham concludes that this demonstrates the need to develop specific supportive networks for caregivers of PWAs. This article addresses that need.

\section{Contextual framework}

The fundamental principles and techniques of group work were employed throughout the sessions, from pre-group interviews to the termination phase. Using self-assessment questionnaires at the introduction of the themes maximised group discussion and emphasised the synergistic properties of group work. Although one member reported that after each exercise she felt "turned inside out", it should nonetheless be noted that the enthusiasm generated within the sessions often required the leader to contain the discussion within the prescribed time limits.

The author strongly subscribes to the principles of conscientisation and the basic tenets of Paulo Freire's work, which essentially moves into an empowerment-orientated paradigm; this in turn leads to the notion of education as the practice of freedom. Hence broadening horizons to incorporate critical consciousness formed the theoretical framework of these sessions. Members found that not only were they in control of what themes were explored, but this helped them to recognise their own worth and afforded them some degree of control over their own lives. This was not empty rhetoric for the author as a group facilitator, who initially made the reasonable assumption that students ultimately witness the potency of such a method in facilitating their own progress on tapping into their own strengths. These dialogical elements affirmed the author's belief in the value of facilitating functional communication with students. 
Dominelli (2004) agrees that a critical, reflexive approach highlights the transferable elements of knowledge and skills. Here the students were able to develop a different narrative by participating in different types of experiences, which assisted in reformulating an alternative understanding and way of acting upon their world (Dominelli, 2004:5). Freire's egalitarian relationship, which has become popularised in education, provides an alternative and appropriate perspective to members of the group. Once they became accustomed to this perspective, it served to meet their group goals. The intersecting of the public and private was of undoubted benefit. The ethos of a strengths perspective was not only empowering, but also fed into students' confidence levels as they owned the process of introspection and challenged convention. Yet another working hypothesis, which served the group well, was the resilience of the human spirit, which permeated all identified themes.

\section{Group composition}

The group comprised five female students between the ages of 20-29 years. Twenty-four sessions were held weekly for $1 \frac{1}{2}$ hours with inter-changeable venues determined by the group. The members dictated the duration, venue and frequency of the sessions, objectives and activities, and the termination of the group meetings.

Upon completion of a questionnaire, which was formulated by the author, pre-group interviews were held. The selection of group members was ultimately determined by criteria derived by them. At the outset rules were stipulated and adhered to throughout the life span of this closed group, with strong emphasis on confidentiality. Periodic self-evaluations of both the group facilitator and members were undertaken, utilising the format designed by Corey and Corey (1997).

Group members' initial audit of feelings surfaced after their weekly exposure to HIV-positive persons from their client population. The poignant question they posed to supervisors was: "How do we take care of our own feelings after we have counselled an HIV/AIDS patient?"

Hesse (2002) acknowledges the concept of "compassion fatigue", which is a reality confronting and experienced by student counsellors. Kubler-Ross (1995:50) succinctly summarises the caregivers' emotions:

You never share your frustrations and your negativity because you keep a lid on all your frustrations and your negativity because you can't go round sobbing and crying or beating the doctors up. And so you keep this nice, smiling front. And after a while you are just waiting to explode. And if you don't explode, then you will be totally drained.

This is what the burnout syndrome is!!!!!!

This article explores the pertinent issues that were addressed within the support group sessions. The themes are outlined below.

\section{Stress management}

Van Dyk's (2007) South African studies on personal coping mechanisms employed by 193 caregivers alluded to the following: 


\begin{tabular}{|l|c|}
\hline Coping mechanisms & $\%$ \\
\hline Social activities with family and friends & 33 \\
\hline Regular physical activities (walking, running, etc.) & 27.9 \\
\hline Listened to music, read, watched movies or played computer games & 25.1 \\
\hline Rest and sleep & 19.3 \\
\hline Religious activities & 18.5 \\
\hline Attended support groups & 16.1 \\
\hline Relaxation activities (meditation and breathing exercises) & 9.1 \\
\hline Ate healthy foods & 5.7 \\
\hline Extra courses and workshops & 5.3 \\
\hline Shopped & 3.2 \\
\hline Alcohol and pills & 2 \\
\hline Cooked and cleaned & 1.6 \\
\hline Bingeing and crying & 1.6 \\
\hline
\end{tabular}

Issues on stress management as central to this theme were intensively discussed including, amongst others, warning signs and identifying resources that are available to them without incurring further monetary costs.

Nature was identified as nurturing and allowing members a "cheap" and effective avenue to deal with the stress of the day. The power of the law of nature was contextualised and compared with their lives. Excerpts from the Brahma Kumaris World Spiritual University Message to The Earth Summit in 1992 were adapted for this use. It called for the following:

\section{Nature's law of balance - the power to judge}

- Rocks and stones and the power to discriminate;

- Earth and the power to co-operate;

- Air and the power to pack up;

- Trees and the power to tolerate;

- Water and the power to merge;

- Fire and the power to face;

- Time and the power to withdraw.

Members unpacked their own mental pollution and connected it with the elements of nature, which sometimes is peaceful, and at other times turbulent and destructive.

It was concluded that the principle of entitlement, the inalienable human right, is what is necessary to restore belief that "you have to care for yourself first, before you extend your caring to others!" Hence the Personal Bill of Rights by Sichel (n.d.) was explored and members duly adapted it for their purposes. The exercise evoked numerous responses which clearly indicated that group members are occasionally harshly critical of themselves in a way which retards their personal progress.

Coupled with the exercise on their rights, an innovative Gratitude List assisted in motivating group members to move beyond their developmental areas. They created a list of the many 
precious and wonderful aspects of their lives; this personalised compilation illustrated to them the overwhelming power of positive thinking and living. Amongst other things, members itemised the following: strength, education, good health, belief in God or a higher power, ability to help themselves, intelligence and a sense of humour.

This list was compiled and documented in their self-care manual as a resource for the group members' library.

Play was also identified as pivotal to relieving stress and found to be a low priority in members' hectic work schedules. Kubler-Ross (1995) rightly notes that success and control are vital, but so is play. She adds that human beings have an innate desire to play, to release, to let go, to dispel stress and tension, but we suppress the urge to play and forget that it's there. Playing could be defined very individualistically - playing with a pet, persons or inanimate objects. Singing, dancing, swimming, cooking or anything else that a person sees as fun can relieve stress. Play acts as mental floss in our lives that promotes a homeostatic balance between work and leisure. If work is identified as a passion in one's life, why is it that we often feel burnt out? Should it not rather feed into our wholeness and contribute to optimising our service delivery? Do work and play always have to remain separate, or can they be conflated to maximise the human experience? Members noted, for example, how the ubiquitous cell phone, although necessary, has invaded leisure time and interrupts our after-hours activities. Could not accepting the call adversely affect your productivity and be of detriment to your immediate career? Is the telephone a priority and does ignoring its persistent ring cause further stress? Can the fusion of work and play hamper our lives? Perhaps this delicate dance needs creative self exploration!

Do we not only need to be reminded that not so long ago as infants our days were constituted purely of play, but also that we can learn to play productively as adults? (Kubler-Ross \& Kessler, 2001).

The group attempted to list some of the areas that were peculiar to the members to break their routine of their lives. These included:

- Read the comic strip first instead of the front page of the newspaper;

- Watch a humorous movie/ sitcom;

- Wear fun underwear/outfits;

- Listen to a radio station you don't usually tune into.

Some of the suggestions offered by Coetzee (2001) were also added to the list.

- Change your music preference, even for one day/week; read the newspaper starting at the last page, if you normally start reading at the beginning; wear your watch on the other arm every Wednesday and/or Saturday; rearrange the furniture in your room - even if you change it back again after one month; get out of bed on the other side; write short personal notes to yourself with your left hand if you are right-handed and vice versa; and brush your teeth with the opposite hand.

- Basically group members were required to do something "silly" or pleasure-inducing and totally innocuous to significant others. After experimenting with the above, members reported that these "out of character activities" not only evoked levity, but also demonstrated that creativity needed to be injected into their daily routine and that they had 
to believe in the possibility that it would add to a more meaningful existence. Kubler-Ross and Kessler (2001) caution that you either play now or pay later.

\section{Transgender}

Participants expressed ambivalent feelings about transgender clients and identified their inherent inability to consciously interrogate their own perceptions of this issue. It is evident that they needed to extend their moral comfort zones to the point of critiquing their own interpretations of what was awkward and discomforting for them. Confronting their collective disapproval required an acknowledgement of the complexities of pursuing an alternate life style.

Questioned on possible areas of discomfort, group members immediately alluded to the following that fed into their lack of confidence when addressing this area:

- Limited/lack of knowledge around sexuality;

- Static notion of identity created by religion and spirituality;

- Definition/clarification of sexual terminology;

- Resolving dissonant feelings about sexuality;

- Expressing genuine openness and honesty despite, for example, internal feelings of ambiguity, and creating internal congruence;

- Discomfort with cultural biases;

- Dismantling their present erroneous conceptions.

An effective exercise undertaken within the group to explore these areas yielded a rich and passionate discussion, which included recounting members' own personal odyssey with sexuality. This illustrated how their perceptions either promoted or hampered their understanding. They reflected on the enormity of their ignorance about transgender and struggled with maintaining non-judgemental attitudes. Dominelli (2004) argues that maintaining a non-judgemental stance requires us to draw a distinction between the person and his/her behaviour; the students attempted to understand the person, but disapproved of the behaviour. As much as they conceded that they were passionate about maintaining egalitarian Social Work principles, they required further dialogue and interaction around concomitant transgender issues, since it would become a substantive reality in their lives as practitioners. Marshal (2001) contends that while clients have much to teach counsellors, they are not responsible for our learning. Rather the initiative should emanate from the counsellors to ensure that they learn, "engage the literature, the community and the world".

\section{Meditation}

Johnson (1997:158) defines meditation as a silent, internal process in which an individual attempts to focus his/her attention on only one thing at a time. The author and group members recognised that this can be a very difficult, diverse and challenging task. But by virtue of the fact that our minds are restless, stillness needs to be deliberately incorporated into our repertoire as counsellors. It was accepted that this unconventional method was novel, but nonetheless worthy of exploration. There is a plethora of instruction manuals/books on the art of meditation, but it was agreed that we essentially required an "uncomplicated and easy manual to follow", which upon investigation did not yield immediately encouraging results. Hence various techniques were contemplated by members, who initially appeared apprehensive about meditation, but concluded that they were prepared to experiment with a myriad of 
techniques prior to commencement. Some obtrusive methods appeared difficult and needed to be demystified for implementation to suit the group environment.

The objective of identifying and tailoring psychological skills management was given spontaneous recognition in meditation. Our specific purpose was to attain greater mental strength, concentration, stability and equipoise in day-to-day practical life (Mumukshananda, 2002). Members conceded that uncluttering their minds was pivotal to emotional health, which could maximise self-care and management.

A meditation instructor introduced us to the most general techniques, which included the following five steps:

Step 1 - Preparation and posture

Step 2 - Breathing

Step 3 - Centring

Step 4 - Visualisation and imagery

Step 5 - The word.

On numerous occasions we novices transgressed these steps, but the teacher was able to skilfully tailor them to meet our purposes and simultaneously assuage our anxiety. We assiduously practised daily at home; however, as protégés we continued to rely on the periodic assistance of our teacher. In retrospect, we still find it an illuminating daily experience as we try incrementally to develop some degree of proficiency.

\section{Music/dance/movement therapy and guided imagery}

Dance movement therapy is a psychotherapeutic use of movement and dance through which a person can engage creatively in a process to further their emotional, cognitive, physical and social integration (ADMT, n.d.). This physical activity was used to complement other exercises undertaken in the session and also to emphasise the patterns of feeling and thinking that invariably promote personal growth. Music, chosen by members as an accompaniment, was appropriate and effective. The benefits included increasing self-awareness; coherence between thoughts, feelings and action; articulating and managing overwhelming feeling/thoughts; locating inner resources through contained creative play; checking the impact of self on others; examining inner and outer realities; and increasing social interaction to develop a trusting relationship.

The group experienced this innovative therapeutic form as "flying out of my centre" and also reported that it was exhausting yet exhilarating.

Guided imagery and music is a technique in which the act of listening to music is combined with a relaxed state of the body in order to evoke imagery for the purpose of self-actualisation (www.onwellness.info/0...music.../music-therapy-ageless). The combination is conducive to maximising the inner journey which promotes healing. This method, based on humanistic therapy, is greatly influenced by Maslow and Jung. On completion of these exercises, members noted that not only were they highly active, but served to relieve inner stress and tension. One member noted that "singing aloud and out of tune" served to revitalise her, despite her arduous and tiring day. The one member who was pregnant at that time remarked that just exposing her to music and dance therapies served to reconcile inner feelings of frustration and exhaustion, and helped to somehow navigate her towards her spiritual being. 


\section{Formalised story telling}

The use of a journal and timeline validated for members their thoughts and feelings at pivotal stages in their lives (Miller, 1999). They also engaged in "life-telling" which also provided a rich narrative about themselves which was consistent with their present feeling and thoughts. They maintained interactive dialogue about sometimes sensitive issues pertaining to their past, which undoubtedly warranted further therapeutic intervention. One member in particular was duly referred for further individual therapy on the recommendation of the leader. The wealth of information generated by this exercise also promoted group cohesion and optimised our group experience.

Muller (2006) advocates a "storying culture". He notes if there is a richness of stories available in our memory, it serves as a "bed" on which you can lie. He notes that the sharing of simple stories can be powerful instruments of care. Comments from members about the therapeutic effect of this exercise proved gratifying and progressively manoeuvred us toward healing. We constantly asked ourselves "What is this encounter supposed to teach me?"

\section{Spirituality and the resilience of the human spirit}

Kubler-Ross (1995:80) warns that we have to make the transition from an age of science/technology and materialism into a new age of genuine and authentic spirituality. She adds that a distinction must be made between religiosity and spirituality - which is an awareness that there exists something far greater than we are, something created by the universe, that we are an authentic and vital component of it, and that we do add to its evolution.

Kasiram, Partab, Dano and Greunen (2003) maintain that the challenge in truly accessing spirituality is central to care-giving: valuing service to people and appreciating the unifying rather than the dividing principles of spirituality will effectively allow spiritual access.

This theme called into direct question the difference between religion and spirituality, and whether contemplating each separately confused rather than clarified issues. Feeling impelled to understand our own religious beliefs and how they informed our identities was at the core to our comprehension of this incredibly lengthy discussion. Time constraints prevented the group from exploring more nuanced and textured narratives. Members recounted and reflected on the effect religion had in their lives and maintained that ritual provided an anchor and was an indisputable fount of their living. The spiritual oasis, we agreed, is what one as an individual contributes to the universe and returns to daily to draws sustenance from, which gives one the impetus to continue. One member declared that she was "not a Christian, but a church goer!" Yet another commented on present decorum and how this contributed to her patients assuming that she was very pious because she wore a rosary to work. Critiquing these areas was both agonising and elevating, and demonstrated the extreme difficulty of confronting this contentious issue. Although some statements had the effect of annoying and agitating some members, this was ultimately not harmful to group cohesion and co-operation. Engaging in the exercise assisted in blurring boundaries and highlighting our own areas of discomfort. One captivating comment made by a member that elicited spontaneous discussion was that "we need to rejoice in the fact that we are not HIV positive". This statement encapsulated the sentiment shared by the group. They eventually compromised by saying that "life has to be celebrated".

\section{Death and dying}

Research (Ferreira et al., 2000; Lehmann \& Zulu, 2005; Smit, 2005; Van Dyk, 2007) has established a clear connection between HIV/AIDS caregiver burnout and bereavement 
overload. Students also encountered feelings of despair and doom when working with issues of death.

The demands on the group of working with issues of death can be both challenging and painful. As Getzel and Mahony (1993) point out, caregivers have to bear witness to tragic loss. She adds that the need for support, recognition and finding an outlet for cumulative grief responses is a sine qua non for workers serving PWAs.

The students had been exposed to 12 lectures in their final year on Bereavement Counselling on the following themes: phases of grief, tasks of mourning, art of conveying condolence, principles of grief counselling, AIDS and grief, children and grief, cross-cultural perspectives on death, attitudes towards pain, dying and death, grief reactions and practices, social status of the deceased, social status of the bereaved, and rituals of death, funerals and mourning.

This module, taught by the author, provided students with adequate knowledge and skill, but left little opportunity to broaden and deepen their understanding of their own feelings about and/or fear of death. What was identified as crucial in the discussions was that one needs to assess the following:

- What is the meaning of MY life?

- What do I want from it?

- How can I create the life I desire?

- Am I fully functional at present?

Death and living are integral to the human condition. Undoubtedly culture and religion impact on our understanding of death. When confronted with death, the preciousness of life becomes glaringly obvious. Human service professionals not only encounter their clients' feelings about death, but they themselves are acutely aware of their own mortality. Kubler-Ross and Kessler (2001) note that in the school of life, dealing loss is a major component of the curriculum. However, this prophetic phase is sometimes difficult to deconstruct and demands validation and positive connotation of what constitutes one's life. In the oscillation of life, can we determine a definite beginning and end?

Time out for personal reflection, as recommended by Corey and Corey (1997), was used to initiate the discussion on death, dying and living. Central to this discussion were pertinent issues which included the following:

- Identifying with the fears that one experiences when one thinks about one's own death;

- Listing specific things group members are not doing presently that they would like to do;

- Identifying how the fact that they will die gives meaning to their present life;

- In what ways do group members think their present fears of death and dying will affect the choices they make in the future;

- Writing a brief description of what they might do if they had only six months to live.

Many of the discussions evolved from total denial and accusations of being "too morbid" to reminiscing and eventually conceding that members need to create their own comfort zone on these questions, since they highlight the implications of their own demise.

Kubler-Ross, a pioneer who wrote extensively on the stages of dying when working with PWAs in her book AIDS: The Ultimate Challenge (1993), emphasises the five stages of dying, which members were able to identify with in their own work with PWAs. The intersection of 
the personal and professional was easily demonstrable upon completion of these sessions for the students.

\section{The therapeutic value of humour}

Seriousness is equated with responsibility, when in fact, I think we could be much more responsible if we had more joy and laughter in our lives. (Deepak Chopra)

Human service practitioners, and especially those working with persons with life-threatening diseases, are confronted with the occupational hazard of severe stress in their professional lives. Their compassion is supposed to be unconditional and unrelenting. Is it therefore insensitive and unethical for them to use humour in their professional lives, or can this be construed as radical healthcare? Of importance is a guiding ethical principle, which should always be adhered to, that at no stage should client confidentiality and professionalism be compromised when practitioners are engaging in jocular activity. At no time should a caregiver ridicule, belittle or become sarcastic (Ball, n.d.).

Parrish and Quinn (1999) maintain that caregivers who successfully manage the unique demands of providing care use humour to release tension and anxiety. In a work environment involving pain and suffering, humour can serve to build purposeful relationship with clients.

In her lectures the author advocates incorporating jocular activity. The results have proven to be not only successful, but have ensured a responsive and attentive class. The levity contained within even a potentially morbid module such as Bereavement Counselling has demonstrated that students were excited and enthusiastic about the lecture, without devaluing the seriousness of the content. Moreover, the author's levity incited and stimulated the students' sense of humour, which could be considered an adjunct to the author's present teaching methodology.

Laughter is a self-refilling medicine, for the more you laugh, the more you laugh (Kubler-Ross \& Kessler, 2001:161).

Craig (2001:55) summarises the psychological and physiological effects of laughter.

- Psychological effects include: buffers and moderates the physical effects of stress, improves mood in coping with sadness and loss, adjunct to psychotherapy, reduces anxiety, improves performance and teamwork, coping with terminal illness, hospitalisation and major medical procedures.

- Physiological effects include: longevity, reduces pain and improves pain threshold, enhances relaxation response, reduces stress hormones (e.g. cortisol), improves immunity, reduces stress hormones and buffers against the immunosuppressive effects of stress, improves blood and lymph flow, increases oxygenation, lowers blood pressure and exercises muscles.

Group members attempted to relate our narratives on humour and our relationship with laughter, quoting anecdotal incidents that evoked laughter. Dominelli (2004) correctly asserts that "new" narratives allow for new possibilities to open up. Members confidently recounted these incidents without fear of reprisal from others in the group. Parrish and Quinn also note that storytelling and human nature conspire beautifully to produce laughter and humour naturally in a group environment. In order to facilitate discussion, members answered a brief questionnaire, which contained the following questions:

- What is your definition of humour?

- Specify who in your life tickles your fancy? 
- Do you think you are funny/witty?

- What in life will you not see humour in?

- Do you remember a funny joke? If so, how often and when will you use it?

- Do you think that you use humour to de-personalise issues?

- Do you always want a captivate audience to tell a joke?

- Do you use humour as a defensive mechanism?

After much discussion, it was deemed imperative to incorporate humour within group members' arsenal of skills and to also broaden their repertoire. It was prescribed that that those who did not possess a humoristic side should immediately undergo "Humour Replacement Therapy".

The ABCs of developing humour by Parrish and Quinn (1999) served as perfect steps to follow. The use of humour is not only pleasure-inducing, but could alleviate stress and elevate the spirit to soaring heights, even if this provides only temporary relief on our stressful days.

\section{Group work: an appropriate method of addressing compassion fatigue}

Dominelli (2004) asserts that groups have been used to promote self-determination and confidence. Support groups for professionals working with PWAs have been recognised as a necessary resource (Grossman \& Silverstein, 1993). The benefit of choosing this method is further endorsed by Greif and Ephross (1997:2), who affirm that participation will lead towards growth, healing, expanding and enhancing social functioning, and learning the expression of democratic citizenship, the practice of self-determination, mutual aid and mutual support.

Students were convinced that the power of participation and the process of sharing would generate a cathartic experience, instil hope, create mutual support, afford discussion on emotional issues, and eventually assist in the development of their own self-care plan. Strug and Podell (2002) also note that emotional support in a group environment adds to the healing presence of group members.

Self-reflection comprised a substantial component of the group process and the benefits were encouraging. Gibson et al. (2002) emphasise two specific advantages for care-workers:

- It provides a means of working through some of the strong emotions that are evoked in care work in order to prevent emotional distress and the long-term problems associated with burnout;

- It prevents care-workers from acting impulsively or unhelpfully with clients.

The synergistic properties of group work would dovetail students' practice and learning, and propel them to develop a better understanding of themselves as social workers. Steinberg (2002) alludes to the exchanging of strengths for personal and interpersonal good. She lists three areas of connections:

- Between people, theory and practice;

- Between need and group purpose;

- Between the psyche of needing help and the psyche of being helpful.

Vertical connections direct members to recognise both the right and capacity of people to have a say over their own affairs, which is one of the ways of engage in mutual aid. 
Horizontal connections provide the correlation between the here and now. By connecting the needs we see with possibilities for group purpose, we develop vision. By connecting intent with professional action, we translate vision into work. Catalysing mutual aid is fundamental to social work and further demonstrates that people have the right to shape their own destinies and possess the inherent capacity to contribute to their own development.

It was agreed that the aim of the sessions would be to constructively develop a self-care plan that would suit members' individual needs, which could ultimately be used as a resource in the future. It was also deemed appropriate to use the group environment to address a fusillade of questions around caring for PWAs. Garside (1993) notes that groups permit the sharing of difficult emotional realities when working with PWAs and their families.

Students were initially requested by the author to explore the following questions individually in preparation for their pre-group interviews:

- Why do you think that the group is best for addressing your concerns?

- What do you view as the purpose of the group?

- What do you specifically envisage getting from the group?

- Are you ready to look critically at your life and undertake an authentic audit of yourself?

- Are you ready to confront unpleasant/awkward issues in your life?

- What are the specific personal issues that you will like to discuss?

- How will this group experience assist in achieving your goal?

- How will this group address planning for self-care management?

- How do you see these sessions contributing as an investment to your future as a social worker?

A life history, seven-page questionnaire (adapted from Johnson, 1997) was also utilised as a point of departure for members, who completed this thought-provoking exercise over two days. Commenting on their experiences they recalled how "agonising, yet necessary" the exercise was and maintained that the comprehensiveness ensured a retrospective cursory understanding of their past. Moreover, they were able to question what "exhausts and what exhilarates" in their lives. The authentic audit of themselves created a scenario of individually acknowledging areas of competence and development. One member maintained that some toxic issues which she often chose to sublimate virtually "glared back at her" for confrontation. The notion of confronting realities is paramount in self-care management.

\section{Post-session reflections and learning curves}

The author felt it prudent to capitalise on students' request for an evaluative tool, because they demonstrated authentic interest in exploring/reflecting on their experiences, which ultimately led to introspection and self-exploration. I further felt compelled and enthused by their identifying with the awesome power of a group experience, where they witnessed theory articulating into practice. The false dichotomy often created by implementing theory into practice was challenged and these two dimensions successfully cohered and harmonised into a meaningful experience for both the leader and group members. Kaslow (2003) notes that facilitating groups is a challenging, humbling and amazing experience. My own experience was indeed not only immensely gratifying and promoted clinical expertise, but indicated and informed necessary changes to my curriculum.

Breton (2002) validates this feeling by noting that mutual-aid group involve not only intragroup solidarity and its healing power, but inter- and extra-group solidarity and its liberating 
power. This mutually beneficial exercise, although exhausting, contributed significantly to the author's professional growth, and harnessed my existing facilitation skills as a group leader and lecturer. The sessions also made clear the inextricable link between self-actualisation and one's own professional development. The self-reflection exercises provided a distinct and cognitive lens from the students' developmental areas and motivated them to move unequivocally towards personal and professional growth. These creative exercises assisted in pushing boundaries, delving into our own past, connecting with how the past informs our present identities, and finally capacitating members and the leader, who in retrospect had to extend her own theoretical comfort zones. In hindsight I understand that not only has this opportunity contributed to my own professional development as a group worker, but it also indicated clearly that professional development is a lifelong process. The preparatory work, which was extensive and rigorous, often presented an avalanche of information that needed to be meticulously chosen to fit group purpose and goal. This was also a learning experience.

Another residual benefit of facilitating this group was the indication of the necessity of including spontaneity in our practice. This forces the student to extend beyond informed conventional wisdom. The eclectic responses from members, who were extremely committed to adhering to group goals, ensured group growth and progression. My incremental theoretical knowledge came to fruition, was tested, challenged, deconstructed and eventually reconstructed.

Moreover, the power relations dynamic pervasive in group work became a learning mechanism for both the members and the leader, who had to be constantly cognisant of its presence. Dominelli (2004:253) makes the point that it is time to reorient power relations within the relationship. In addition, the complexities and ambiguities that underlie our own lives were acknowledged and honestly discussed, which clearly fostered a fruitful and challenging learning experience.

Challenging assumptions and being a critically reflexive practitioner do require their own mental gymnastics, but they did provide the foundation for members to actively question their own existence, which was initially identified as a group goal. A distinguishing benefit of facilitating a group of this nature was that, as the group generated its own creativity it directed me towards exploring my own dormant creativity. Without question the self-imposed solitude engaged in after reading through their evaluations navigated my own professional development and either affirmed or begged change. My passion for group work was nourished after this experience, despite my one very sophisticated error that required more thorough exploration, namely that of spirituality.

Members reported that they felt that the time limit on this theme did not afford them sufficient opportunity for the in-depth discussion they initially envisaged. It was patently obvious that I need to be more flexible and spontaneous about abandoning highly formulated plans for a session and employ alternative techniques that are more conducive to group growth. I remain convinced that conventional wisdom needs to be challenged openly, respectfully and purposively. Although each theme appeared extremely loaded, it served both as illuminating and exploratory. Brook and Davis (1985) point out that we should not expect clients to bare their deepest thoughts and frustrations, while we sympathise from within our sterile bubbles.

\section{CONCLUSION}

Malekoff (2002) rightfully notes that what passes as group work is nothing more than curriculum-driven pseudo-group work, which stamps out spontaneity and creativity. My own experience of facilitating this group with members from the class helped not only to demystify this modality of social work to them, but indeed suggested that conventional and mediocre 
methodologies can be challenged and injected with innovation to sustain interest and make group work an exhilarating, exciting and enduring method of choice. The anti-oppressive lens projected within the group reinforced the notion of reciprocity that was felt both by the leader and members (Dominelli, 2004).

Fox (2002) reflects that in caring for the carers we are not only ensuring optimal care for the PWAs, but that - for the sake of our own survival - we should also be mindful that this is an interdependent relationship. This experience demonstrated that groups can provide a safe environment to expose emotional despondency, compassion fatigue, create an empathetic milieu, ameliorate student burnout and vicarious trauma, alleviate stress, and promote healing. Moreover, it is asserted that self-care should not be relegated to a low priority and regarded as negligible in the lives of healthcare professionals, as this ultimately leads to vicarious trauma. The feeling was that the group environment facilitated discussions on all themes, with the exception of spirituality, which the leader acknowledges is a topic for further exploration. Perhaps it could be included at a more elementary level.

Getzel and Mahony (1993) write that the lessons learnt when working with PWAs are strange and wonderful, and that the experience is worth every minute.

It is strongly suggested that support groups for students working with PWAs become a mandatory resource to ensure optimal service delivery to this client population. This pragmatic, powerful and salutary effect has been epitomised by responses from group members, who have undoubtedly given their stamp of approval to group work as a responsive manner of effectively facilitating individual change and employing effective strategies to manage self-care. They conclusively answered the question "Who cares for the care-giver?" by indicating that this is their own responsibility.

Goldenberg and Goldenberg in Khoza (2006) advise: "Face the fact that you must grow until you die. Develop a sense of the benign absurdity of life - yours and those around you."

\section{REFERENCES}

ADMT (Association for Dance Movement Therapy). (n.d). [Online] Available: http://www. admt.org.uk.

ARMSTRONG, S., BARIYRE, R., FINNEGAN, A., NSUBUGA, L., OTTENWELLER, M., SOZI, C. \& TOWELL, E.A. 2000. Caring for carers- what can be done to reduce burnout in community caregivers of people with HIV/AIDS? Paper presented at the $13^{\text {th }}$ International AIDS Conference, South Africa, 9-14 July 2000.

BALL, B.P. (n.d.) Humour and therapy. [Online] Available: www.humortheory. com/index.php/basil-hall-humor.

BRAHMA KUMARIS WORLD SPIRITUAL UNIVERSITY. 1992. The power of nature and how we can help re-create a new and peaceful world. Earth Summit, Rio de Janeiro, Brazil.

BRETON, M. 2002. A rewarding group worker's journey. Social Work with Groups, 25(1/2):43-61.

BROOK, E. \& DAVIS, A. (eds) 1985. Women, the family and social work. London: Tavistock Publishers.

CHOPRA, D. 2008. [Online] Available: http://www.chopra.com/namaste/jul08/perfecthealth. 
COETZEE, A. 2001. I think, I feel, I am! A new approach to self-empowerment. Pretoria: Lapa Publishers.

COREY, G. \& COREY, M.S. 1997. I never knew I had a choice $\left(6^{\text {th }}\right.$ ed $)$. London: Brooks/Cole Publishers.

CRAIG, H. 2001. New frontiers in medicine, The body as the shadow of the soul. Melbourne: Hill Publishers.

CUNNINGHAM, S.B. 2003. The support needs of caregivers, the body. AIDS Survival Project News.

CWIKEL, J.G., KACEN, L. \& SONUM-NEVO, V. 1993. Stress management consultation to Israeli social workers during the Gulf War. Health and Social Work, 18(3):172-182.

DOMINELLI, L. 2004. Social work: theory and practice for a changing profession. Cambridge: Cambridge University Press.

FERREIRA, V.M.B., FERREIRA, R.D.C.M. \& GJOURUP, N.B. 2000. Thinking about stress to avoid burnout in health care providers. Paper presented at the $13^{\text {th }}$ International AIDS Conference, South Africa, 9-14 July 2000.

FOX, M. 2002. A question of survival: who cares for the carers? Journal of Social Work Practice, 16(2):185-190.

GARSIDE, B. 1993. Physician mutual aid group: a response to AIDS related burnout. Health and Social Work, 18(3):259-266.

GETZEL, G.S. \& MAHONEY, K.F. 1993. Confronting human finitude: group work with people with AIDS, social work with groups. Journal of Community and Clinical Practice, 16(1):27-41.

GIBSON, K., SWARTZ, L. \& SANDENBERG, R. 2002. Counselling and coping. Oxford: Oxford University Press.

GREIF, G.L. \& EPHROSS, P.H. (eds) 1997. Group work with populations at risks. Oxford: Oxford University Press.

GROSSMAN, A.H. \& SILVERTEIN, C. 1993. Facilitating support groups for professionals working with people with AIDS. Social Work, 38:144-151.

HESSE, A.R. 2002. Secondary trauma: how working with trauma survivors affects therapist. Clinical Social Work Journal, 30(3):293-309.

JOHNSON, S.L. 1997. The therapist's guide to clinical intervention. The 1-2-3's of treatment planning. London: Academic Press.

KASIRAM, M., PARTAB, R., DANO, B. \& VAN GREUNEN, J. 2003. Managing HIV/AIDS: guidelines for counsellors, caregivers and faith-based practitioners. South Africa: Print Connection.

KHOZA, V. 2006. Vicarious trauma: the impact of caring and self care strategies for carers. In: KASIRAM, M., PARTAB, R. \& DANO, U. (eds) HIV/AIDS in Africa - the not so silent presence. South Africa: Print connection.

KUBLER-ROSS, E. \& KESSLER, D. 2001. Life lessons how our mortality can teach us about life and living. Great Britain: Simon \& Schuster.

KUBLER-ROSS, E. 1995. Death is of vital importance. On life, death, and the life after death. USA: Station Hill Press. 
KASLOW, F.W. 2003. Descendants' memories and legacies: post holocaust highways and byways to and in Chile. Journal of Family Psychotherapy, 14(2):69-80.

LEHMANN, U. \& ZULU, J. 2005. How nurses in Cape Town clinics experience the HIV epidemic. AIDS Bulletin, 14(1):42-47.

MAIL AND GUARDIAN, 11 June 2008. (Online) Available www.thoughtleader.co.za/.../11/ legacy-what.

MALEKOFF, A. 2002. The power of group work with kids: lessons learned. United Kingdom: Haworth Press Inc.

MARSHALL, J.L. 2001. Pastoral care and the formation of sexual identity: lesbian, gay, bisexual and transgendered. American Journal of Pastoral Counselling, 3(3/3):101-111.

MAZODZE, O., RICHARDS, K. \& PENNYMON, W. 2004. Enhancing HIV/AIDS counsellor training programmes and counsellor organizational practice by examining counsellors' emotional experiences when counselling HIV/AIDS patients. Paper presented at the $15^{\text {th }}$ International AIDS Conference, Bangkok, Thailand, 11-16 July 2004.

MILLER, R. 1999. Caring for carers. [Online] Available: informahealthcare.com/ doi/abs/10.1080/13561820701327822.

MULLER, J. 2006. [Online] Available: www.julianmuller.co.za/Download.../11-Palliativecare-and-family.html.

MUMUKSHANANDA, A.A. 2002. Meditation and its preparation. Kolkata: Trio Publishers. [Online] Available: $\underline{w w w . a d v a i t a o n l i n e . c o m . ~}$

PARRISH, M.M. \& QUINN, P. 1999. Laughing your way to peace of mind: how a little humour helps caregivers survive. Clinical Social Work Journal, 27(2):203-211.

SICHEL, M. (n.d.) Personal Bill of Rights. [Online] Available: http://www.psybersquare. com/me/billofrights.html.

SMIT, R. 2005. HIV/AIDS in the workplace: perceptions of nurses in a public hospital in South Africa. Journal of Advanced Nursing, 51(1):22-29.

STEINBERG, D.M. 2002. The magic of mutual aid. Social Work with Groups: A Journal of Community and Clinical Practice, 25(1-2):31-38.

STRUG, D. \& PODELL, C. 2002. A bereavement support group for paediatric HIV/AIDS case managers and social workers: helping members cope with dying children. Social Work with Groups: A Journal of Community and Clinical Practice, 25(3):61-75.

VAN DYK, A.C. 2007. Occupational stress experienced by caregivers working in the HIV/AIDS field in South Africa. African Journal of AIDS Research, 6(1):49-66.

VAN EYSSEN, B. 2003. Relatives and strangers at helm of AIDS care. 26 November 2003. [Online] Available: www.iol.co.za.

Website consulted: $\underline{w w w . o n w e l l n e s s . i n f o / 0 . . . m u s i c . . . / m u s i c-t h e r a p y-a g e l e s s . h t m l . ~}$

Ms Rubeena Partab, School of Social Work and Community Development, University of KwaZulu-Natal, Durban, South Africa. 